Webology, Volume 17, Number 1, July, 2020

\begin{tabular}{|l|l|l|l|}
\hline Home & Table of Contents & Titles \& Subject Index & Authors Index \\
\hline
\end{tabular}

\title{
Towards Information Anxiety and Beyond
}

\author{
Muhammad Asif Naveed* \\ *Corresponding author, Department of Library and Information Sciences, University of \\ Sargodha, University Road, 40100, Sargodha, Pakistan. ORCID: 0000-0002-9104-8143. \\ E-mail: asif.naveed@uos.edu.pk, masifnaveed@yahoo.com
}

\section{Mumtaz Ali Anwar \\ Department of Information Management, University of the Punjab, Quaid-i-Azam Campus, Canal Road, Lahore, Pakistan. E-mail: anwar.mumtazali@yahoo.com}

Received January 25, 2020; Accepted June 20, 2020

\begin{abstract}
This study provides an overview of the historical background of information anxiety, critically reviews the existing framework, and proposes a new framework for information anxiety that goes beyond information retrieval and information seeking in the contemporary information environment to inform policy and practice. The proposed framework comprises of six dimensions, namely: task conceptualization; need recognition; finding information; evaluating information; accessing information; and using information. This study also outlines certain correlatives of information anxiety based on the existing research. It also outlines theoretical and practical implications of information anxiety on information retrieval and information literacy (IL) instructions. It concludes with directions for future research on information anxiety considering the contemporary information landscape. This study would be a worthy contribution in the existing research on information anxiety as no such study appeared so far.
\end{abstract}

\section{Keywords}

Information Anxiety; Information Literacy; Information Retrieval; Information Seeking Anxiety; Library Anxiety; Pakistan 


\section{Introduction}

The conception of anxiety associated with information, perhaps, began with human thinking and has been identified for hundreds of years. It was Sir Francis Bacon who first mentioned this concept in 1605 in his book entitled The Advancement of Learning by saying, as quoted by Girard and Allison (2008 p. 111), "[t] hat in spacious knowledge there is much contristation, and that he that increaseth knowledge increaseth anxiety" (Bacon, 1605). It was nearly 400 years later that the term information anxiety emerged in the best-selling book entitled "Information Anxiety" by Richard Saul Wurman published in 1989. Research examining people's anxiety associated with information related tasks was meagre before the mid-1980s (Fine, 1984). Several scholars had approached this research area in one way or the other. This area resultantly went through so many transitions and different labels were used for its representation. A perusal of the published research on peoples' anxiety associated with information resulted in three different concepts dealing with users' anxiety while interacting with information namely, library anxiety, information seeking anxiety, and information anxiety.

Naveed and Anwar's (2019) nested model of information anxiety explains these concepts simultaneously distinct and related. This model represented these concepts as a series of nested fields, with information anxiety as the general area of investigation, information seeking anxiety being seen as a subset of the field, and library anxiety as a further sub-set of information seeking anxiety. The first concept focuses on information users' anxiety within the library (Mellon, 1986) whereas the second concept deals with anxiety in the course of information seeking anytime, anywhere (Erfanmanesh, Abrizah \& Karim, 2012; Naveed, 2017). While information anxiety is a broader term that goes beyond the four walls of the library and the discourse of information seeking; these three concepts existed independently and parallelly and attracted much attention from the researchers of their respective fields. The terms library anxiety and information seeking anxiety emerged in the field of library and information science whereas the term information anxiety came from the discipline of computer science. Library anxiety and information seeking anxiety were investigated in the academic context whereas information anxiety was researched in the workplace context (Naveed \& Anwar, 2019).

\section{Definition of Information Anxiety}

Wurman, an expert in information architecture, defined information anxiety as the state "produced by the ever-widening gap between what we understand and what we think we should understand. It is the black hole between data and knowledge, and it happens when information doesn't tell us what we want or need to know" (Wurman 1989, p. 34; Wurman, Leifer, Sume and Whitehouse, 2001, p.14). He further suggested that "information anxiety can afflict us at any level and is as likely to result from too much information as too little information" (p. 44). He also remarked that the uncertainty surrounding the existence of a particular piece of information 
is a major cause of information anxiety. According to Eklof (2013), it "is brought on by the desire to absorb as much information as possible, feeling overwhelmed by the amount of information being filtered to you, and not being able to process this information" (p.247). Bawden and Robinson (2009) defined it as "a condition of stress caused by the inability to access, understand, or make use of, necessary information" (p.6). The possible causes of information anxiety might include insufficient information, information overload, poorly organized information, and lack of understanding or incapability to navigate with the contemporary information landscape (Bawden \& Robinson, 2009; Kennedy 2001).

Wurman's definition captured the interests of the business leaders as many of them were experiencing "challenges of organizational memory loss" (Girard \& Allison, 2008, p. 111). However, there was no empirical evidence to support Wurman's hypothesis at that time and considered by some "to be pure fiction, ... and relegated to the abyss of business hype" (p.111). Later on, this concept was substantiated by a few research projects providing empirical evidence for this phenomenon. Of those research projects, Girard (2005a) examined the knowledge management issues in a government setting of Canada and reported information anxiety as a distinct entity which was quite different from information overload and suggested information anxiety as a fact rather than fiction.

The study of Allison (2006) questioned Girard's results and reported information anxiety as synonymous with information overload and suggested it as a fallacy. However, in a later study, Allison (2008) affirmed the results of Girard (2005a) and proposed information anxiety as "a real organizational malady worthy of the attention of senior leaders" (Girard \& Allison 2008, p. 111). Then, Girard and Allison (2008) also recommended more investigations addressing information anxiety "to further refine the malady, its causes, and ways to combat its debilitating effects" (p. $111)$.

Girard (2005b) had reported negative association between task frequency and information anxiety levels whereas some later studies reported positive relationship between task complexity, quantity of distractions and information anxiety (Baron 1986; Groff, Baron, \& Moore, 1983; Wood, 1986). However, Ojo (2016) reported no correlation between age, gender, and information anxiety of the undergraduate students. Shedroff (2001) described that information anxiety can have many forms. The first is the 'frustration with inability to 'keep up' with the amount of data present in our life. The second is the frustration with the quality of what we encounter especially what passes as news - which refers to the need of being up-to-date and constantly informed. Thirdly, the guilt associated with not being 'better informed', of not being able to keep up with the amount of data masquerading as information. Fourth, probably not the last, is a dangerous hubris that develops for 'knowing things first'. 


\section{Wurman's Framework of Information Anxiety}

The conceptual framework of information anxiety (IA), as perceived by Wurman (1989), consisted of five sub-components, namely: a) understanding information (UI), b) information overload (IO), c) knowing information exists (IE), d) finding information FI), and, e) accessing information (AI). The first component is about either no understanding or lack of understanding with the information. Even when information is available, it must be fully understood to be useful to the user of information. The possible illustration of this can be an individual who fails to understand the basic questions that need to be answered. The second, an information overload occurs when information users feel overwhelmed by the amount of information to be understood in information problem solving. The information users experience such feelings during the information seeking and retrieval process especially when they lack information seeking skills. It is difficult to overcome information overload at the beginning stages as it is at the end.

Thirdly, information users also experience the issue of not knowing if certain information exists to complete the task in hand. Fourthly, lack of understanding about where to find what also leads to feeling of failure, frustration, and uncertainty. It is difficult for information users to solve information-based problems when not knowing where to find the needed information. Lastly, even if the user is able to figure out where to locate the needed information, it is not necessary that he/she also possesses the key to access it. Issues such as copyright laws and items from a private collection, or distant library or password-protected database may restrict users' access to the required information. Such situations can be a discouraging outcome after a long information search process.

\section{Need for Reconceptualization of Information Anxiety}

Though many scenarios are described within Wurman's framework of information anxiety, it is a much broader term encompassing several degrees of intensity and can be caused by many other factors. Furthermore, the framework of information anxiety presented by Wurman in 1989 also needed to be expanded because it limited the information activities up to information access only and mainly centered on information retrieval process except the first component, namely, 'not understanding information'. Since Wurman was an information architect, he considered information access as the last step of the information retrieval process and limited his framework to it. Thus, the consideration of information anxiety framework from the perspective of information users got overlooked. The information activities, such as comprehension, synthesis, evaluation, information use, etc., were not covered in Wurman's framework which needed to be considered. It is also interesting to note that Wurman used the term information anxiety when there was a traditional information landscape and web was in its embryonic or infancy stage. Therefore, there was a need to the re-conceptualization of information anxiety so that the information professionals might have a holistic view of information related anxieties which go 
beyond the process of information retrieval. If the information professionals focus only on single dimension of information anxiety related to the course of information retrieval, most of the other aspects of information anxiety would be overlooked. Considering the contemporary information environment, the current research proposes a new framework for information anxiety.

\section{Looking for a New Framework}

Information anxiety is a much broader concept embracing information seeking or retrieval anxiety, experienced by anyone, anytime, and anywhere, but including other anxieties associated with certain other aspects of information such as task conceptualization and definition, need recognition, comprehension, synthesis, evaluation, and use of information. It refers to the feeling of discomfort when people interact with information for solving information-based problems in multiple contexts such as academia, workplace and everyday life. Eklof (2013) defined it as "a guilty feeling, as if it is the responsibility of the person to understand all of the information to which he or she has access" (p. 247). These feelings may not only cause different 'cognitive, emotional, and behavioral effects' but may also affect an individual's self-efficacy and performance. This study proposes a new framework of information anxiety that goes beyond information retrieval and information seeking (Figure 1).

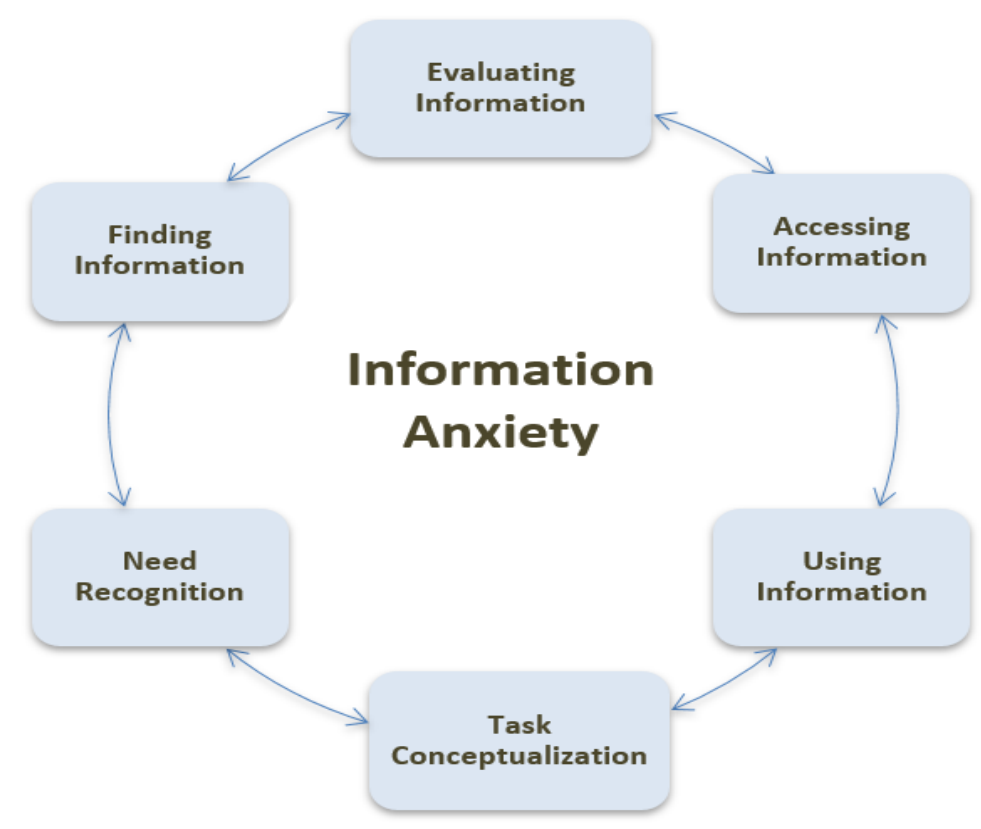

Figure 1. New Framework of Information Anxiety

The new framework comprises of six dimensions, namely: Task Conceptualization (TC); Need Recognition (NR); Finding Information (FI); Evaluating Information (EI); Accessing Information (AI); and Using Information (UI), where information users mainly experience anxiety while interacting with information. This framework is not always a linear and step by 
step process. It encourages a variety of alternative strategies such as jumping around, branching off, or looping back (Figure 2). These dimensions either contribute individually or their mathematical sum to the feelings of information anxiety. It may be expressed mathematically as:

$$
\mathrm{IA}=\mathrm{TC}+\mathrm{NR}+\mathrm{FI}+\mathrm{EI}+\mathrm{AI}+\mathrm{UI}
$$

In this framework, task conceptualization deals with the understanding of information task. Task conceptualization is the foundation for the development of information needs. If an individual lacks task conceptualization and fails to define the task, it may lead to the poor recognition of information need which triggers the information seeking process. Users can become anxious if they do not have appropriate task conceptualization and definition abilities. If an individual does not have clarity about 'what do I need to do', how can he/she determine as to what is required to complete the task related to 'what information do I need to do'? Task conceptualization is the primary component in the framework of information anxiety.

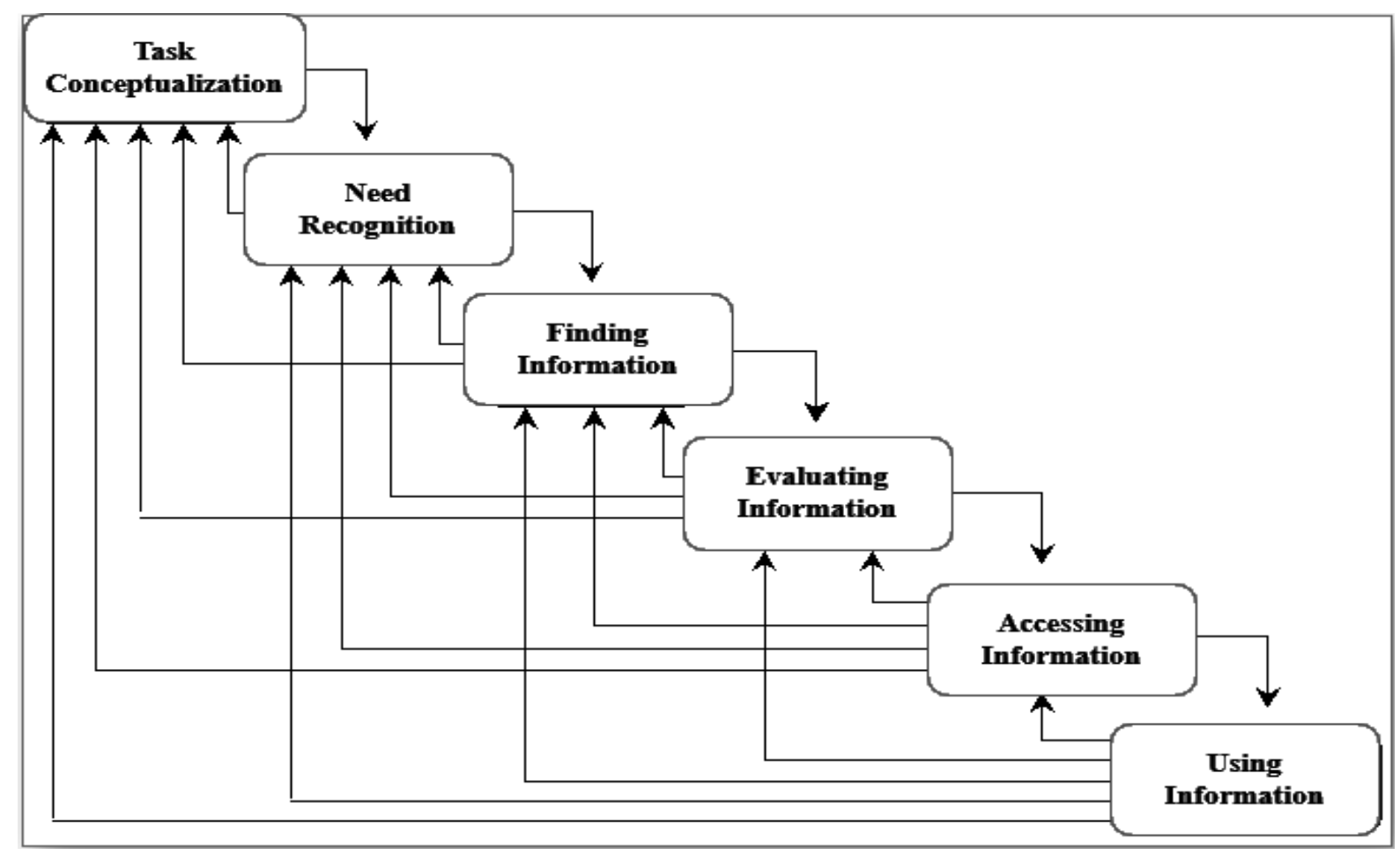

Figure 2. New Framework is not Linear

The second component, need recognition, is concerned with the recognition of a person's actual information need. It is his/her general idea of what is needed to know. In other words, it is the rational and precise description of certain questions, about the task in hand, that require answers. People, sometimes, fail to recognize what they need to know - the information need. Their ability may vary in the precision and the extent to which they are aware of their information need. They may also feel incapable to specify their information need precisely into search terms 
or keywords enabling them to find the required information. In addition, the mismatch between search terms expressed by the seeker and the index terms used by the search tool may also bring frustration and anxiety to the information seeker. The difficulties in appropriate recognition, articulation, and precise description of information need may cause feelings of discomfort and uncertainty among information users. For instance, a university student who does not understand an easy question needed to be answered for a class assignment. The student cannot move forward for his/her research without an appropriate understanding of the question. The student cannot determine the nature and extent to which information needed without understanding of a question. In other words, a person with a health issue seeking to inform himself/herself so as to contextualize medical advice. Without understanding of what is required to resolve that health issue, he cannot move forward with his/her task. The feelings of discomfort such as frustration, stress, anxiety, and fear may begin to sprout up at this step.

Finding information is the third component of this newly proposed framework of information anxiety. People may find information in a variety of ways using different strategies from multiple information sources in varied contexts. It incorporates a number of activities such as brainstorming about all possible information resources and selecting the best ones, developing search strategies, searching or browsing, facing information overload, identification, selection, and location of needed information sources. When people lack awareness about potential information sources and have poor searching skills, they can experience information overload. The inability of the information seeker in finding the relevant information may also cause frustration and uncertainty. An illustration of this could be an individual not knowing where and how to find required information and experiencing information overload due to poor searching skills. The feelings of being overwhelmed by the amount of information can occur at any stage of information searching process especially in beginning stages. Information seekers can also face the issue of not knowing if certain information exists because he/she obviously not sure about the answer to question or if his/her question specifically been addressed in scholarly literature. The uncertainty about whether or not the research will produce valid information if none exists also brings feelings of discomfort.

The fourth component, evaluating information, is concerned with people's difficulties in determining the relevance, reliability, validity, accuracy, authoritativeness, authenticity, timeliness, bias and credibility of information and its sources. The people's inability for information evaluation also one of the key factors that brings feelings of anxiety. If the information seekers lack confidence about the usefulness of information they have gathered, their confidence about the decisions made will also be low which ultimately affect the quality of decision making. The critical evaluation of information and its sources directly influence the efficiency and effectiveness of decisions human make about everyday life. If these decisions are related to business and health issues, the cost of poor decision making may even be worse and nor-repairable. 
The fifth factor, accessing information, also causes anxiety among information seekers. Even if an information seeker is able to locate the required information, it is not necessary that he/she possesses the key to access it. The issues of no access or lack of access to needed information bring anxiety among information users. The failure of someone in accessing the needed information after a long and tedious information search process is a discouraging outcome causing frustration. For example, if an information user has successfully searched, identified, selected, and even located his needed information, he/she fails to access, due to whatever reason, the required information. The failure in accessing needed information also brings feeling of discomfort such as anxiety, uncertainty, stress, and fear.

Using information is the last component of the proposed framework of information anxiety. It is concerned with the people's physical and mental activities to incorporate information into their existing knowledge base to make sense of their lives and situations. Information is interpreted and utilized differently by different individuals and groups. People's information use is dependent on certain factors such as their prior knowledge, their affective states, intellectual abilities, prior skills, and physical disabilities, if any. Information use incorporates a number of activities such as reading, extracting, collecting, organizing, comparing information from different sources, comprehending, analyzing, evaluating, internalizing, synthesizing, creating meaning, making decisions, and applying information. If people lack understanding of information and fail to make sense of their situations, the feelings of frustration and anxiety may arise. Understanding of economic, legal, social and ethical issues surrounding the use of information can alleviate anxiety associated with information usage.

\section{Correlatives of Information Anxiety}

A perusal of the published research revealed three different but related concepts dealing with users' anxiety while interacting with information, namely: library anxiety, information seeking anxiety, and information anxiety. Library anxiety deals with a sense of powerlessness when initiating information search, and in feelings of being lost, unable to find one's way around, and afraid to approach staff within a library (Mellon, 1986). Bostick (1992) conceptualized library anxiety as a multi-dimensional construct and developed a Library Anxiety Scale (LAS) consisting of 43 statements which grouped into five sub-dimensions, namely, staff barriers, affective barriers, comfort with the library, barriers with library knowledge, and mechanical barriers. Since its development, LAS has been utilized extensively to assess library anxiety among undergraduates across different library environments had a few modifications and translations owing to different educational, cultural, and geographical grounds (Anwar, AlKandari \& Al-Qallaf, 2004; Shoham \& Mizrachi, 2004; Swigon, 2011; Van Kampen, 2004). Later on, LAS was reported as outdated and inappropriate for its continued application to assess library anxiety in digital library environment (Anwar et al., 2004; Kwon, 2004). Considering the unsuitability of LAS in digital library environment, Anwar, Al-Qallaf, Al-Kandari, and Al-Ansari 
(2012) developed and validated a new library anxiety scale (AQAK) consisted of 40-items distributed in five factors, namely, information resources, library staff, user knowledge, library environment, and user education. It was worth noting that this study identified 'user education' as a factor in library anxiety indicating the future directions for information literacy instruction.

There was a need to address users' anxiety while seeking information from a variety of sources, including the library, the web and human. The study of Erfanmanesh, Abrizah, and Karim (2012) appeared to be the first that used the term 'information seeking anxiety' dealing with users' feelings of discomfort, uncertainty, and fear experienced during the course of information seeking, either manual or computer-based, at anytime, anywhere and from anyone. It goes beyond the physical space of a library, which may include - but is not limited to library anxiety and includes anxieties while looking for information from a variety of sources including the library, the web and human. This study developed and validated an Information Seeking Anxiety Scale (ISAS) to measure information seeking anxiety among postgraduates. This scale consists of 47-items which were clustered into six sub-dimensions, namely, barriers with information resources, computer and internet barriers, library barriers, searching barriers, technical barriers, and topic identification barriers. Since the development of ISAS, it has been used by a number of studies to measure information seekers' anxiety (Erfanmanesh, Abrizah, \& Karim, 2014a, 2014b; Naveed \& Ameen 2016a, 2016b, 2016c, 2017a, 2017b; Rahimi \& Bayat, 2015). Later on, Naveed (2017) provided an analytical and critical review of research on information seeking anxiety which indicated the manifestation of anxiety among students while interacting with information.

Information anxiety is even more general embracing both library and information seeking anxiety but including other anxieties associated with certain other aspects of information such as task definition, need recognition, access, comprehension, synthesis, evaluation, usage, etc. It encompasses several degrees of intensity and can be caused by multiple scenarios as suggested in the proposed framework. These three concepts, such as library anxiety, information seeking anxiety, and information anxiety existed independently, parallelly and captured attention of scholars from their respective disciplines. Library anxiety and information seeking anxiety were addressed by a number of investigations in the academic context whereas information anxiety was investigated by a few studies in the workplace context. None of the existing studies established a relationship between these concepts and provided synthesis of research at a single place. Keeping this in mind, Naveed and Anwar (2019) not only traced the historical developments of these concepts but also proposed a nested model of information anxiety which represented information anxiety as the general and broader concept nesting information seeking anxiety as its sub-set and library anxiety as a further sub-set.

Table 1 outlined certain correlative of users' anxiety associated with information identified from the existing research conducted over time. The three terms such as library anxiety, information 
seeking anxiety, and information anxiety were utilized interchangeably to develop correlative presented in Table 1. The reason for highlighting these correlatives was to inform information professionals both instructors and practitioners so that they may be able to keep these in mind while planning information literacy instructions. However, this study did not claim, by no means, to list all the studies reporting the correlatives of information anxiety. There may be other studies reporting these correlatives which we could not identify.

Table 1. Correlatives of information anxiety

\begin{tabular}{|c|c|c|}
\hline Cor & Research Projects & Nature of Relationship \\
\hline $\begin{array}{l}\text { Task orientation } \\
\text { (Task complexity, } \\
\text { distractions, and } \\
\quad \text { frequency) }\end{array}$ & $\begin{array}{l}\text { Baron, 1986; Groff, Baron } \\
\text { \& Moore, 1983; Girard, } \\
\text { 2005b; Wood, 1986; } \\
\text { Girard, } 2006\end{array}$ & $\begin{array}{l}\text { - Levels of information anxiety increases as the task } \\
\text { complexity increases. } \\
\text { - The level of information anxiety in complex task } \\
\text { increase as the quantity and force of distractions } \\
\text { increases. } \\
\text { - No relationship existed between type of } \\
\text { managerial task and information anxiety } \\
\text { - Levels of Information anxiety decreases as the } \\
\text { task frequency increases. }\end{array}$ \\
\hline $\begin{array}{r}\text { Tech } \\
(\text { Com } \\
\text { Internet }\end{array}$ & $\begin{array}{r}\text { Jerabek } \\
\text { Kordinak, } \\
\text { Onwueg } \\
\text { Naveed \& } \\
\text { Shoham \& } \\
\end{array}$ & $\begin{array}{l}\text { - There is inverse relationship between information } \\
\text { anxiety and proficiency for computer \& internet } \\
\text { because the levels of information anxiety } \\
\text { decrease as the proficiency with computer and } \\
\text { internet increases. }\end{array}$ \\
\hline $\begin{array}{l}\text { Sociodemographic } \\
\text { (Age, gender, social, } \\
\text { background) }\end{array}$ & $\begin{array}{l}\text { Erfanmanesh, 2016; } \\
\text { Erfanmanesh, Abdullah \& } \\
\text { Karim, 2014a; Naveed \& } \\
\text { Ameen, 2016a, 2016 b, } \\
\text { 2016c; 2017; Rahimi \& } \\
\text { Bayat, } 2015\end{array}$ & $\begin{array}{l}\text { - No correlation appeared between information } \\
\text { anxiety and age. } \\
\text { - Information anxiety appeared sensitive to gender } \\
\text { as females were more anxious as compared to } \\
\text { males. } \\
\text { - No relationship reported between information } \\
\text { anxiety and social background (i-e urban and } \\
\text { rural). }\end{array}$ \\
\hline $\begin{array}{l}\text { Educational } \\
\text { (Field of study, } \\
\text { program of study, stage } \\
\text { of study, research } \\
\text { productivity; academic } \\
\text { procrastination) }\end{array}$ & $\begin{array}{l}\text { Erfanmanesh 2016; } \\
\text { Erfanmanesh, Abdullah \& } \\
\text { Karim, 2014a; Naveed \& } \\
\text { Ameen, 2016a, 2016 b, } \\
\text { 2016c, 2017; Onwuegbuzie } \\
\text { \& Jiao, 2000 }\end{array}$ & $\begin{array}{l}\text { - No relationship existed between field of study and } \\
\text { information anxiety. } \\
\text { - Levels of information anxiety decrease as the } \\
\text { program of study, stage of study, and research } \\
\text { productivity increase. } \\
\text { - As the levels of information anxiety increase, the } \\
\text { academic procrastination also increases. }\end{array}$ \\
\hline $\begin{array}{l}\text { Language proficiency } \\
\text { (English) }\end{array}$ & $\begin{array}{c}\text { Jiao \& Onwuegbuzie, } \\
\text { 1999; Naveed, 2016; } \\
\text { Naveed \& Ameen, 2016; } \\
\text { Rahimi \& Bayat, 2015; } \\
\text { Sinnasamy \& Karim, 2014 }\end{array}$ & $\begin{array}{l}\text { - There is inverse relationship between information } \\
\text { anxiety and English language proficiency } \\
\text { because the levels of information anxiety } \\
\text { decrease as the proficiency for English language } \\
\text { increases. }\end{array}$ \\
\hline Emotion & $\begin{array}{l}\text { Jan, Anwar, \& Nosheen, } \\
\text { 2016a; 2016b; 2018; } \\
\text { Savolainen, } 2014\end{array}$ & $\begin{array}{l}\text { - Negative relationship appeared between } \\
\text { information anxiety and emotional intelligence } \\
\text { because information anxiety decreases as the } \\
\text { levels of emotional intelligence increase. }\end{array}$ \\
\hline $\begin{array}{c}\text { Behavioral } \\
\text { (Avoidance) }\end{array}$ & Abusin \& Zainab, 2010 & $\begin{array}{l}\text { - Information anxiety triggers information and } \\
\text { library avoidance behaviors. }\end{array}$ \\
\hline
\end{tabular}




\begin{tabular}{c|c|c|c}
\hline Critical thinking & $\begin{array}{c}\text { Kwon, 2008; Kwon, } \\
\text { Onwuegbuzie \& } \\
\text { Alexander, 2007 }\end{array}$ & $\begin{array}{c}\text { - Inverse relationship appeared between information } \\
\text { anxiety and critical thinking because information } \\
\text { anxiety decreases as the levels of critical } \\
\text { thinking increase }\end{array}$ \\
\hline Learning styles & Onwuegbuzie \& Jiao, 1998 & $\begin{array}{c}\text { - Students who like structure, lack persistence, and } \\
\text { who are self-motivated and peer-oriented } \\
\text { learners tend to have highest levels of } \\
\text { information anxiety. }\end{array}$ \\
\hline Pelf-efficacy beliefs & $\begin{array}{c}\text { Jiao \& Onwuegbuzie, } \\
1999 ; \text { Gross \& Latham, } \\
2007\end{array}$ & $\begin{array}{c}\text { Levels of information anxiety increase as the } \\
\text { perceived self-efficacy for scholastic } \\
\text { competence, intellectual ability, creativity, and } \\
\text { social acceptance decrease. }\end{array}$ \\
\hline Piao \& Onwuegbuzie, 1998 & $\begin{array}{c}\text { Students with self-oriented and other-oriented } \\
\text { perfectionism tend to have high levels of } \\
\text { information anxiety. }\end{array}$ \\
\hline
\end{tabular}

\section{Conclusion and Implications for Future Research}

The advancement in information and communication channels has historically prompted anxiety associated with information in response to its increasing volume and breadth. The earlier invention of movable printing and later the internet have significantly influenced the volume and speed of the distribution of information. The former, was limited to the production of individual physical copies of documents whereas the later enabled not only far greater speed of information distribution but also allowed content creation at the same time. Information anxiety is not a new concept, but the scope of information we interact with today is much larger than the past due to ease of content creation and unlimited distribution of information enabled through the World Wide Web. The increased quantity of information and users' poor information literacy skills are the primary factors creating an environment where information anxiety occurs. The former requires a technical solution for the reduction of information overload by eliminating duplicate data through the design of information retrieval systems which might reduce the size of the problem and become a part of ultimate solution. Whereas the later requires information users to be educated and empowered with necessary skills to navigate contemporary information landscape confidently rather than anxiously.

Understanding information anxiety and its roots will help information scientists and instructors, especially those engaged in information literacy instructions, to minimize its effects on people's personal as well as professional lives. Therefore, there is a need for more investigations examining information anxiety, in a variety of contexts with different populations from multiple geographical areas of the world. The dimensions of task conceptualization, evaluating information, and using information need to be focused more because these are not explored so far in the existing research on information anxiety. Such inquiries will generate useful insights to inform policy and practice for information literacy instructions. The need-based information literacy instructions will foster an ecosystem of thoughts enabling people to make a responsible 
and generative information use and sift through and discard that which is damaging, false, or useless. The navigation of human with information landscape is always an imperfect endeavor, but that their interaction with information is a journey rather than a safe harbor, and it is possible to teach and learn strategies to alleviate information overload and anxiety.

Information scientists aim to empower students with necessary skills through information literacy instructions so that they may be able to navigate contemporary information environment confidently rather than anxiously. Information professionals need to develop a people-centered information literacy program considering their psychological barriers in the digital environment. The students' psychological barriers especially the concept of information anxiety needs to be incorporated in information literacy instructions so that the students be made aware about its existence (Naveed, 2017). According to Wurman (1989), when people understand negative feelings and are interested in the information they encounter, information anxiety is less likely to occur among individuals which will lead to self-confidence and information efficacy. The skills with regard to ICTs, English language, emotional intelligence, self-efficacy and critical thinking should be incorporated in information literacy curriculum as individuals with high levels of these skills experience lower levels of information anxiety. In addition, information professionals also need to incorporate those learning styles and perfectionism behaviors that helps information users in reducing information anxiety (Table 1). The students also need to be informed about the appropriate time to contact reference and research librarians for reception of professional assistance to combat information anxiety. It would not only produce independent, self-regulated, life-long learners, capable of sifting right information from wrong and differentiating credible content from propaganda and sponsored results, but also reduce the pressure of users' queries on reference desk and save precious time of library staff. If the library staff is aware about the dimensions of information anxiety, the provision of help desk services can be improved.

The future research on information anxiety needs be conducted in multiple directions. Firstly, indepth inquiries are needed for the exploration of information anxiety construct among students of all levels and among a variety of professionals. Secondly, efforts need to be made for the development of an information anxiety scale considering the contemporary information landscape so that information anxiety can be measured in all its dimensions and need-based curriculum for information literacy can be developed for the alleviation of anxiety with information related tasks. Thirdly, information anxiety needs to be examined in a variety of contexts such as academia, workplace, and everyday life using different populations from a variety of geographical locales of the world. Lastly, the relationship of information anxiety with other related phenomena such as critical thinking, emotional intelligence, personality traits, ICT proficiency, research efficacy, academic achievement, academic procrastination, language proficiency, etc., also needs to be examined in future inquiries so that the corelates of information anxiety may be identified. 


\section{Acknowledgement}

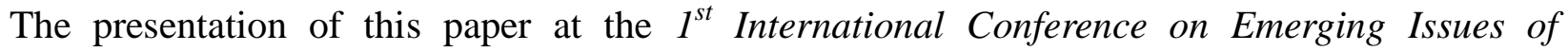
Information Landscape (ICEIL), held on February 28 - March 01, 2019 at University of Sargodha, Sargodha, is acknowledged.

\section{References}

Abusin, K. A., \& Zainab, A. N. (2010). Exploring library anxiety among Sudanese university students. Malaysian Journal of Library \& Information Science, 15(1), 55-81.

Allison, M. P. (20060. The effects of quality improvement high-performance team membership on information anxiety. California, US: Touro University International.

Allison, M. P. (2008). Information anxiety: Comparison of samples within the United States Air Force and linear analysis of the political-military affairs strategist career field. US: Air Command and Staff College.

Anwar, M. A., Al-Qallaf, C. L., \& Al-Kandari, N. M., \& Al-Ansari, H. A. (2012). AQAK: A library anxiety scale for undergraduate students. Journal of Librarianship and Information Science, 44(1), 36-46.

Anwar, M. A., Al-Kandari, N. M., \& Al-Qallaf, C.L. (2004). Use of Bostick's Library Anxiety Scale on undergraduate biological sciences students of Kuwait University. Library \& Information Science Research, 26(2), 266-283.

Bacon, F. (1915). The advancement of learning. London: Dent.

Baron, R. S. (1986). Distraction-conflict theory: Progress and problems. Advances in Experimental Social Psychology, 19(1), 1-40.

Bostick, SL. (1992). The development and validation of the Library Anxiety Scale. Doctoral dissertation, Wayne State University.

Bowden, D., \& Robinson, L. (2009). The dark side of information: Overload, anxiety and other paradoxes and pathologies. Journal of Information Science, 35(2), 180-191.

Eklof, A. (2013). Understanding information anxiety and how academic librarians can minimize its effects. Public Services Quarterly, 9(3), 246-258.

Erfanmanesh, M. A. (2016). Information seeking anxiety: Effects of gender, level of study and age. Library Philosophy and Practice (e-journal). Retrieved January 15, 2020, from http://digitalcommons.unl.edu/libphilprac/1317

Erfanmanesh, M. A., Abrizah, A., \& Karim, N. H. A. (2012). Development and validation of the Information Seeking Anxiety Scale. Malaysian Journal of Library \& Information Science, 17(1), 21-39. 
Erfanmanesh, M. A., Abrizah, A., \& Karim, N. H. A. (2014a). The prevalence and correlates of information seeking anxiety in postgraduate students. Malaysian Journal of Library \& Information Science, 19(2), 69-82.

Erfanmanesh, M. A., Abrizah, A., \& Karim, N. H. A. (2014b). Information seeking anxiety: Concept, measurement and preliminary research. International Journal of Information Science \& Management, 12(1), 47- 64.

Fine, S. F. (1984). Research and the psychology of information use. Library Trends, 32(4), 441-460.

Girard, J. P. (2006). Where is the knowledge we have lost in managers? Journal of Knowledge Management, 10(6), 22-38.

Girard, J. P. (2005a). Combating information anxiety: A management responsibility. Management of Organizations: Systematic Research, 35, 65-79.

Girard, J. P. (2005b). Taming enterprise dementia in public sector organizations. International Journal of Public Sector Management, 18(6), 534-545.

Girard, J. P., \& Allison, M. (2008). Information anxiety: Fact, fable or fallacy. The Electronic Journal of Knowledge Management, 6(2), 111-124.

Groff, B. D., Baron, R. S., \& Moore, D. L. (1983). Distraction, attentional conflict, and dislike behavior. Journal of Experimental Social Psychology, 19, 359-380.

Gross, M., \& Latham, D. (2007). Attaining information literacy: An investigation of the relationship between skill level, self-estimates of skill, and library anxiety. Library \& Information Science Research, 29(3), 332-353.

Jan, S. U., Anwar, M. A., \& Warraich, N. F. (2016a). Library anxiety and emotion perception among the undergraduate social sciences students: A relationship study. Behavioral \& Social Sciences Librarian, 35(2), 52-63.

Jan, S. U., Anwar, M. A., \& Warraich, N. F. (2016b). Library anxiety, library use and academic performance of undergraduate students in Pakistan. Library Review, 65(8/9), 564-577.

Jan, S. U., Anwar, M. A., \& Warraich, N. F. (2018). The relationship between emotional intelligence, library anxiety, and academic achievement among the university students. Journal of Librarianship and Information Science, 1-12.

Jerabek, J. A., Meyer, L. S., \& Kordinak, S. T. (2001). Library anxiety and computer anxiety: Measures, validity, and research implications. Library \& Information Science Research, 23(3), 277-289.

Jiao, Q. G., \& Onwuegbuzie, A. J. (1999). Library anxiety among international students. Retrieved January 15, 2020, from https://files.eric.ed.gov/fulltext/ED437973.pdf

Jiao, Q. G., \& Onwuegbuzie, A. J. (2017). The impact of information technology on library anxiety: The role of computer attitudes. Information Technology and Libraries, 23(4), 138-144. 
Jiao, QG., \& Onwuegbuzie, A. J. (1998). Perfectionism and library anxiety among graduate students. Journal of Academic Librarianship, 24(5), 365-372.

Jiao, QG., \& Onwuegbuzie, AJ. (1999). Self-perception and library anxiety: An empirical study. Library Review, 48(3), 140-147.

Kennedy, S. D. (2001). Finding a cure for information anxiety. Information Today, 18(5), 40-41.

Kwon, N. (2004). Library anxiety and Library Anxiety Scale in the digital library environment. Journal of the Korean Society for Library and Information Science, 38 (2), 29-47.

Kwon, N. (2008). A mixed-methods investigation of the relationship between critical thinking and library anxiety among undergraduate students in their information search process. College \& research libraries, 69(2), 117-131.

Kwon, N., Onwuegbuzie, A. J., \& Alexander, L. (2007). Critical thinking disposition and library anxiety: Affective domains on the space of information seeking and use in academic libraries. College \& Research Libraries, 68(3), 268-278.

Mellon, C. A. (1986). Library anxiety: A grounded theory and its development. College \& Research Libraries, 47(2), 160-165.

Naveed, M. A. (2016). Exploring information seeking anxiety among research students in Pakistan. Libri, 66(1), 73-82.

Naveed, M. A. (2017). Information seeking anxiety: Background, research, and implications. International Information \& Library Review, 49(4), 266-273.

Naveed, M. A., \& Ameen, K. (2016a). Information seeking anxiety among postgraduate students of university. Journal of Behavioural Sciences, 26(1), 142-154.

Naveed, M. A., \& Ameen, K. (2016b). Measuring levels of students' anxiety in information seeking tasks. Pakistan Journal of Information Management and Libraries, 17, 56-68.

Naveed, M. A., \& Ameen, K. (2016c). A mixed-method investigation of information seeking anxiety in Pakistani research students. Pakistan Library and Information Science Journal, 47(2), 24-33.

Naveed, M. A., \& Ameen, K. (2017a). Determining the prevalence and correlates of information seeking anxiety among postgraduates in Pakistan. Libri, 67(3), 205-214.

Naveed, M. A., \& Ameen, K. (2017b). A cross-cultural evaluation of the psychometric properties of Information Seeking Anxiety Scale in Pakistani environment. Malaysian Journal of Library \& Information Science, 22(3), 35-51.

Naveed, M. A., \& Anwar, M. A. (2019). Modeling information anxiety. Library Philosophy and Practice (e-journal). Retrieved January 15, 2020, from https://digitalcommons.unl.edu/libphilprac/2758

Ojo, O. J. M. (2016). Information anxiety and information overload of undergraduates in two universities in South-West Nigeria. Library Philosophy and Practice (e-journal). Retrieved January 15, 2020, from http://digitalcommons.unl.edu/libphilprac/1368. 
Onwuegbuzie, A. J., \& Jiao, Q. G. 1998. The relationship between library anxiety and learning styles among graduate students: Implications for library instruction. Library \& Information Science Research, 20(3), 235-249.

Onwuegbuzie, A. J., \& Jiao, QG. (2000). I'll Go to the library later: The relationship between academic procrastination and library anxiety. College \& Research Libraries, 61(1), 45-54.

Rahimi, M., \& Bayat, Z. (2015). The relationship between online information seeking anxiety and English reading proficiency across gender. Handbook of Research on Individual Differences in Computer-Assisted Language Learning, 449.

Savolainen, R. (2014). Emotions as motivators for information seeking: A conceptual analysis. Library \& Information Science Research, 36, 59-65.

Shedroff, N. (2001). Forms of information anxiety. In R. S. Wurman (Ed.), Information Anxiety 2 (pp. 15-16). Indianapolis, IA: Que.

Shoham, S., \& Mizrachi, D. (2004). Computer attitudes and library anxiety among undergraduates: A study of Israeli B. Ed. students. The International Information \& Library Review, 36(1), 29-38.

Sinnasamy, J., \& Karim, N. H. A. (2014). A correlational study of foreign language anxiety and library anxiety among non-native speakers of English: A case study in a Malaysian public university. The Journal of Academic Librarianship, 40(5), 431-435.

Swigon, M. (2011). Library anxiety among Polish Students: Development and validation of the Polish Library Anxiety Scale. Library \& Information Science Research, 33(2), 144-150.

Van Kampen, D. J. (2004). Development and validation of the Multidimensional Library Anxiety Scale. College \& Research Libraries, 65(1), 28-34.

Wood, R. E. (1986). Task complexity: Definition of the construct. Organizational Behavior and Human Decision Processes, 37(1), 60-82.

Wurman, R. S. (1989). Information anxiety. New York, NY: Doubleday.

Wurman, R. S., Leifer, L., Sume, D., \& Whitehouse, K. (2001). Information anxiety 2. Indianapolis, IA: Que.

\section{Bibliographic information of this paper for citing:}

Naveed, M. A., \& Anwar, M. A. (2019). "Towards information anxiety and beyond." Webology, 17(1), Article 208. Available at: http://www.webology.org/2020/v17n1/a208.pdf

Copyright (C) 2020, $\underline{\text { Muhammad Asif Naveed and Mumtaz Ali Anwar. }}$ 